\title{
B7-H3, B7-H4, Foxp3 and IL-2 expression in cervical cancer: Associations with patient outcome and clinical significance
}

\author{
CHENGLIN HUANG, LEI ZHOU, XIAOHAN CHANG, XIAOAO PANG, \\ HUIJIE ZHANG and SHULAN ZHANG
}

\begin{abstract}
Department of Obstetrics and Gynecology, Shengjing Hospital of China Medical University, Shenyang, Liaoning 110004, P.R. China
\end{abstract}

Received November 2, 2015; Accepted January 12, 2016

DOI: $10.3892 /$ or.2016.4607

\begin{abstract}
The aim of this study was to determine the expression of B7-H3, B7-H4, Foxp3 and IL-2 in cervical cancer tissues, and evaluate the corresponding clinical significance. The expression of B7-H3, B7-H4, Foxp3 and IL-2 in 108 cervical cancer specimens was detected using immunohistochemistry, and their relationship with clinicopathologic parameters was determined. B7-H3, B7-H4 and Foxp3 had high levels of expression in cervical cancer cells $(72.22,80.56$, and $91.56 \%$, respectively). B7-H3 levels were only significantly associated with tumor size $(\mathrm{P}=0.013)$, while $\mathrm{B} 7-\mathrm{H} 4$, Foxp3 and IL-2 levels were significantly associated with International Federation of Gynecology and Obstetrics (FIGO) stage ( $\mathrm{P}=0.023,0.014$ and 0.036 , respectively) and tumor size $(\mathrm{P}=0.045,0.010$ and 0.021 , respectively). Their expression levels were not correlated with age, histologic type, differentiation and lymph node metastasis (all $\mathrm{P}>0.05$ ). Cox regression multivariate analysis confirmed that $\mathrm{B} 7-\mathrm{H} 3$ or $\mathrm{B} 7-\mathrm{H} 4$ overexpression was an independent prognostic factor. In addition, there were significant positive relationships between the expression of B7-H3 and B7-H4 with Foxp3 $(\mathrm{P}<0.001)$. In contrast, the expression of B7-H3 and B7-H4 was negatively correlated with IL-2 $(\mathrm{P}<0.05)$. B7-H3, B7-H4 and Foxp3 may be useful biomarkers in patients with cervical cancer for predicting treatment.
\end{abstract}

\section{Introduction}

Cervical cancer is the second leading cause of cancer-related deaths in women, and the leading cause in some developing countries (1). The occurrence and development of cervical cancer are closely associated with the human immune system. The activation, inactivation and dysfunction of the immune system have drawn increasingly more research interest.

Correspondence to: Dr Shulan Zhang, Department of Obstetrics and Gynecology, Shengjing Hospital of China Medical University, 36 Sanhao Street, Heping, Shenyang, Liaoning 110004, P.R. China E-mail: zs10909@sina.com

Key words: B7-H3, B7-H4, Foxp3, cervical cancer, co-stimulatory molecule, immunohistochemistry
Suppressed immune function may result in accelerated disease progression, and immune escape exerts an important effect on tumor progression. Recent research on $\mathrm{T}$ cell negative regulatory pathways have confirmed the important role of negative co-stimulatory molecules in the tumor immune response. This negative signal is mainly provided by the B7 family, which has become an intense focus of research in cancer immunotherapy. B7-H3 and B7-H4 are newly identified members of the family that are abnormally expressed in tumors. Both molecules have similar patterns of expression. Specifically, the mRNAs are widely expressed in multiple non-lymphoid tissues, including the intestines, stomach, lungs and kidneys, whereas the proteins are only highly expressed in a variety of malignant tumors, such as prostate cancer (2), pancreatic cancer $(3,4)$, lung cancer $(5,6)$, renal cell carcinoma $(7,8)$, and ovarian cancer $(9,10)$, but not in any of the normal peripheral tissues. In a previous study involving 102 patients with cervical cancer, the rate of expression of B7-H4 was $69.6 \%$ (71/102), although the level of expression was not correlated with the clinicopathologic parameters of the tumor (11). A subsequent long-term follow-up study revealed poor prognosis in patients with B7-H4 expression in tumor tissues (11).

Regulatory $\mathrm{T}$ (Treg) cells have significant effects on the blood, tissues and organs, and play an important role in maintaining the stability of the immune system, and tumor immune tolerance and escape due to an immunosuppressive ability (12). Foxp3 is a specific transcription factor expressed in Treg cells. It has been recently reported that the number of Treg cells is significantly increased in some tumors $(13,14)$ that penetrate into the tumor microenvironment, and are involved in the process of tumor immune escape by preventing natural killer (NK) cells and cytotoxic lymphocytes (CTLs) from attacking cancer cells (15). Foxp3 is also expressed in tumor cells, such as pancreatic (16), prostate (17) and gastric cancers (18); however, it has been shown that the expression of Foxp3 varies in different tumor cells, and is even different in the same types of tumors. We speculate that tumor cells expressing Foxp3 may participate in tumor immune escape by stimulating Treg cells. IL-2 is a key antitumor cytokine released during an immune response, and is regulated by lymphocytes and other cells upon stimulation by antigen or mitogen. IL-2 directly affects the function of immune cells and local immune status. IL-2 is an important component of cellular immunity that activates 
CTLs and promotes the differentiation of activated $\mathrm{T}$ cells IL-2 stimulates the proliferation of T cells and enhances their killing effect, and thereby plays an important anti-viral and antitumor role. It has also been shown that the antitumor effect of $\mathrm{T}$ cells is reduced with a decreased level of IL-2. Expression of B7-H3 and B7-H4 may decrease the efficacy of immunotherapy by suppressing the antitumor effect of $\mathrm{T}$ cells and by promoting the function of Treg cells.

In the present study, we sought to identify whether B7-H3, B7-H4, Foxp3 and IL-2 were overexpressed in cervical cancer cells, and to investigate any correlation between the expression of these proteins. What is more, their correlation with clinicopathologic features was analyzed to assess the impact on the progression of the tumor. Furthermore, the prognostic significance of these proteins in cervical cancer was evaluated to provide additional information for the treatment of cervical cancer.

\section{Materials and methods}

Patients and follow-up. Before this analysis, patient information was anonymized and de-identified. All participants provided written informed consent. The entire analysis of tissues was approved by the Institutional Review Board of Shengjing Hospital of China Medical University (ethics approval code, 2013PS47K).

Paraffin cervical tumor tissues from 108 patients treated between 2007 and 2012 in the Department of Gynecology and Obstetrics of Shengjing Hospital affiliated with the China Medical University were obtained. All tissue sections were independently examined by two pathologists to make a final histopathologic diagnosis using the World Health Organization criteria. The classification of cancer clinical stage was in accordance with the 2009 International Federation of Gynecology and Obstetrics (FIGO) criteria.

All of the patients were diagnosed with cancer for the first time. No chemotherapeutic treatments were administered before surgery. The follow-up was carried out according to National Comprehensive Cancer Network (NCCN) guidelines: every month in the first year; every third month in the second year; twice in the third, fourth and fifth years; and annually thereafter. After treatment, all patients were followed up until May 2015.

Immunohistochemistry. Immunohistochemistry was used to determine levels of expression. Four antibodies, including murine monoclonal B7-H3 (ab105922, 1:700 dilution), rabbit monoclonal B7-H4 (ab108336, 1:500 dilution), murine monoclonal Foxp3 (ab22510, 1:50 dilution), and rabbit monoclonal IL-2 antibodies (ab92381, 1:300 dilution) were purchased from Abcam Co. (Cambridge, UK). The staining procedure was performed as described in the manual of an ultrasensitive streptavidin-peroxidase kit (kit 9701; Maixin Bio, Fuzhou, China). Colorectal carcinoma tissue samples known to be positive tissue slices were used as positive controls, while tissues treated with phosphate-buffered saline (PBS) substituted for the primary antibody were used as a negative control.

Evaluation of immunostaining. Immunostaining was scored by two pathologists. Scores representing the percentage of
Table I. Clinical and pathological characteristics.

\begin{tabular}{lc}
\hline Characteristics & $\mathrm{n}(\%)$ \\
\hline Differentiation & \\
Well differentiated (WICC) & $17(15.74)$ \\
Moderately differentiated (MICC) & $77(71.30)$ \\
Poorly differentiated (PICC) & $14(12.96)$ \\
Histology & \\
Squamous cell carcinoma (SCC) & $98(90.74)$ \\
Adenosquamous cell carcinoma (ACC) & $10(9.26)$ \\
Lymph node (LN) metastasis & \\
Absent (-) & $44(40.74)$ \\
Present (+) & $64(59.26)$ \\
Tumor size (cm) & \\
$\leq 4$ & $80(74.07)$ \\
$>4$ & $28(25.93)$ \\
FIGO stage & \\
Ia & $2(1.85)$ \\
Ib & $53(49.08)$ \\
IIa & $44(40.74)$ \\
IIb & $7(6.48)$ \\
III & $2(1.85)$ \\
\hline
\end{tabular}

positive cells were as follows: 0 , no positive cells; $1,1-25 \%$ positive cells; $2,26-50 \%$ positive cells; $3,51-75 \%$ positive cells; and 4, 76-100\% positive cells. Staining intensity was scored as follows: 0 , no staining; 1 , weak staining; 2 , moderate staining; and 3, strong staining. These two scores were then multiplied to yield the final score, resulting in the following scores: $0-2,(-) ; 3-4,(+)$; 5-8, (++); and 9-12, (+++). Two independent observers, who were blinded to the patient materials, scored each section to control for observer error.

Statistical analysis. The correlations between the levels of expression of B7-H3, B7-H4, Foxp3 and IL-2 in different pathologic lesions and the clinicopathologic characteristics were analyzed using a Chi-squared $\left(\chi^{2}\right)$ test. Correlation analysis of B7-H3, B7-H4, Foxp3 and IL-2 protein expression was performed using the Spearman's rank order correlation coefficient. Cancer-related death was used as an endpoint, and Kaplan-Meier survival curves were plotted and compared using the log-rank test for univariate overall survival analysis. The Cox regression model was used for multivariate overall survival analysis. All statistical analyses were performed using SPSS 17.0 software (SPSS, Inc., Chicago, IL, USA). Analyses were performed with two-sided tests; a p-value $<0.05$ was considered statistically significant.

\section{Results}

Patient characteristics. The age range of the 108 patients was 22-67 years (mean, 43.75 years; median, 44.00 years). There were two histologic types of cancer tissue: squamous cell carcinoma, $n=98$; and adenocarcinoma, $n=10$. Tumor 

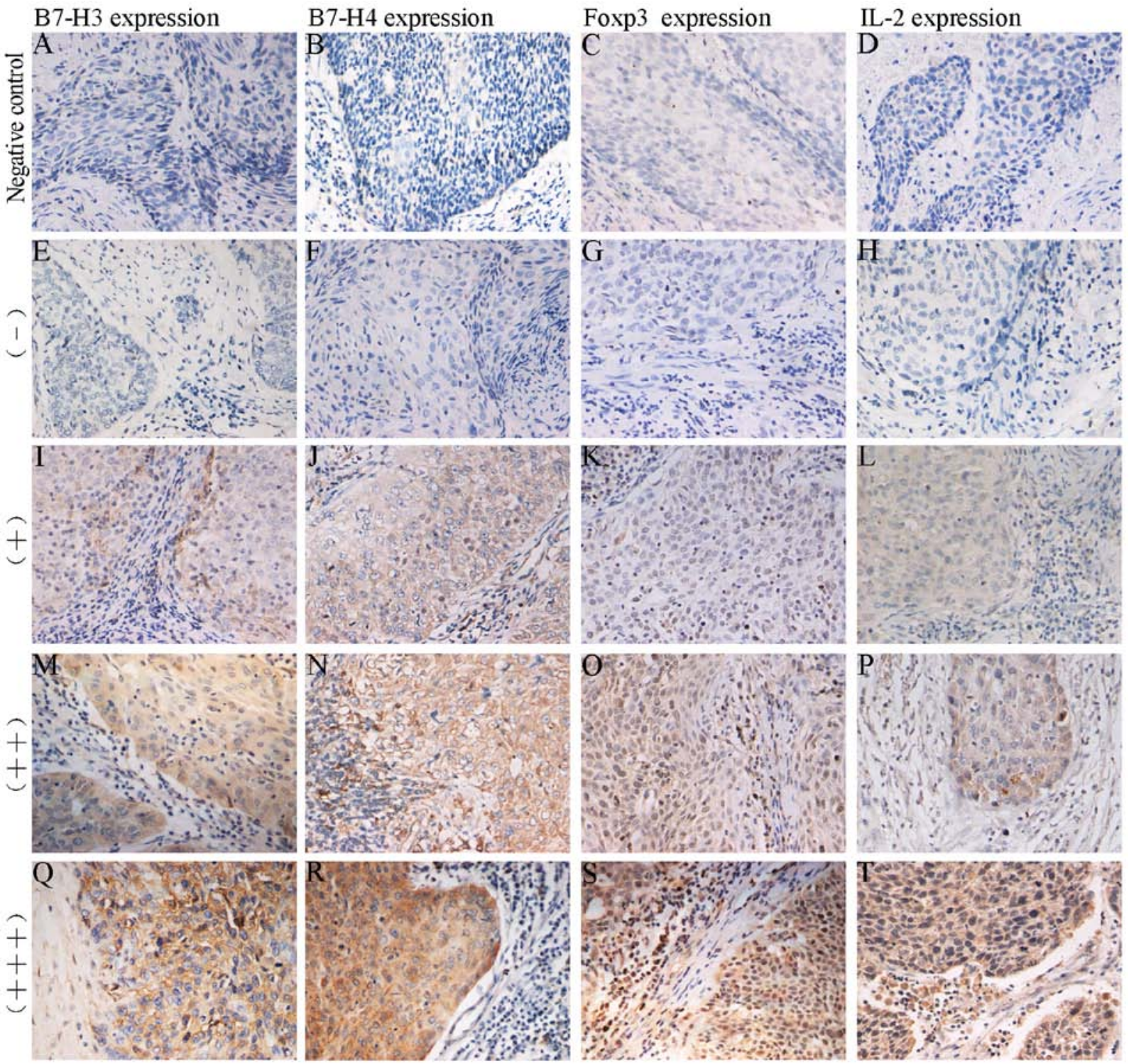

Figure 1. Representative images of B7-H3, B7-H4, Foxp3 and IL-2 antigen expression in cervical cancer (magnification, x400). Column 1, B7-H3; column 2, B7-H4; column 3, Foxp3; column 4, IL-2. (A-D) Negative control; (E-H) negative expression (-), (I-L) weak positive expression (+), (M-P) moderate positive expression (++) and (Q-T) strong positive expression (+++).

differentiation was as follows: well differentiated, $\mathrm{n}=17$; moderately differentiated, $\mathrm{n}=77$; and poorly differentiated, $\mathrm{n}=14$. According to FIGO stage, there were 55 patients in stage I, 51 patients in stage II, and 2 patients in stage III. All of the clinical features, including lymph node metastasis and tumor size, are shown in Table I.

Expression of B7-H3, B7-H4, Foxp3 and IL-2 in cervical cancer (Fig. 1). In the cervical cancer tissues, B7-H3 and B7-H4 were mainly expressed in the cytoplasm of the cancer cells, with minimal expression in the nucleus; there was also a small amount of interstitial expression. Foxp3 expression was located in the $\mathrm{T}$ cell nucleus, and the cytoplasm and nucleus of malignant cervical cancer cells. IL-2 staining was detected in the cytoplasm. Among the 108 specimens, the positive expression rates were as follows: B7-H3, 72.22\% (78/108); B7-H4, 80.56\% (87/108); Foxp3, $91.67 \%$ (99/108); and IL-2, 50.00\% $(54 / 108)$.
Relationship between B7-H3, B7-H4, Foxp3 and IL-2 levels and the clinicopathologic features of the cervical cancer tissues (Table II). Te expression profiles of B7-H3, B7-H4 and Foxp3 were similar. B7-H3 levels were significantly associated with tumor size ( $\mathrm{P}=0.013)$. B7-H4, Foxp3 and IL-2 levels were significantly associated with FIGO stage $(\mathrm{P}=0.023,0.014$ and 0.036 , respectively) and tumor size $(\mathrm{P}=0.045,0.010$ and 0.021 , respectively). The levels of expression of B7-H3, B7-H4 and Foxp3 were not correlated with age, histologic type, differentiation and lymph node metastasis.

Association between B7-H3, B7-H4, Foxp3 and IL-2 expression. There was a positive correlation between the expression of B7-H3 and B7-H4 with Foxp3, and between B7-H3 and B7-H4 expression in cervical cancer; however, Spearman's rank correlation analysis showed that $\mathrm{B} 7-\mathrm{H} 3$ or $\mathrm{B} 7-\mathrm{H} 4$ protein expression was negatively correlated with IL-2 expression in the cervical cancer (the Spearman's correlation coefficient, $r$, 


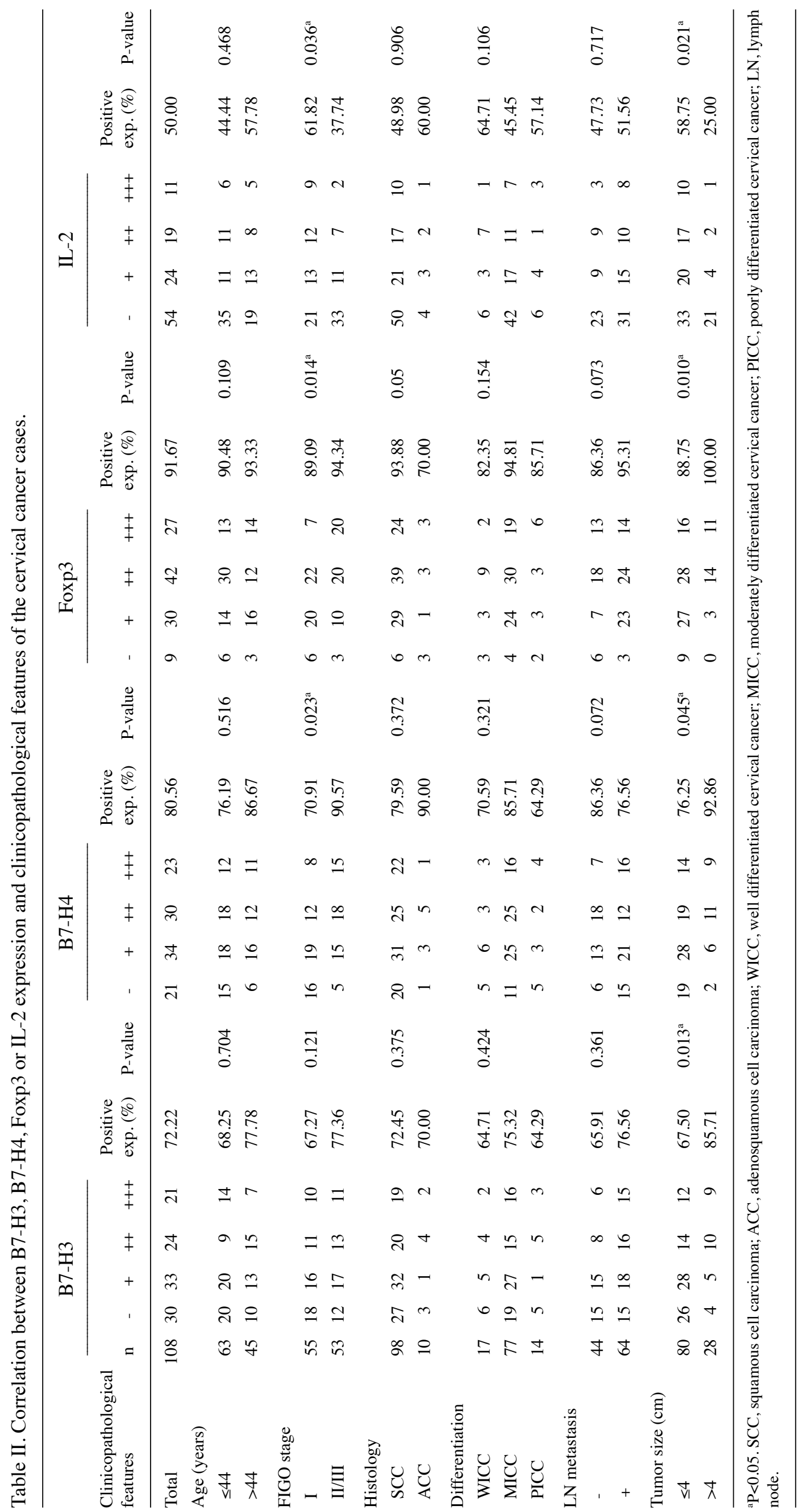



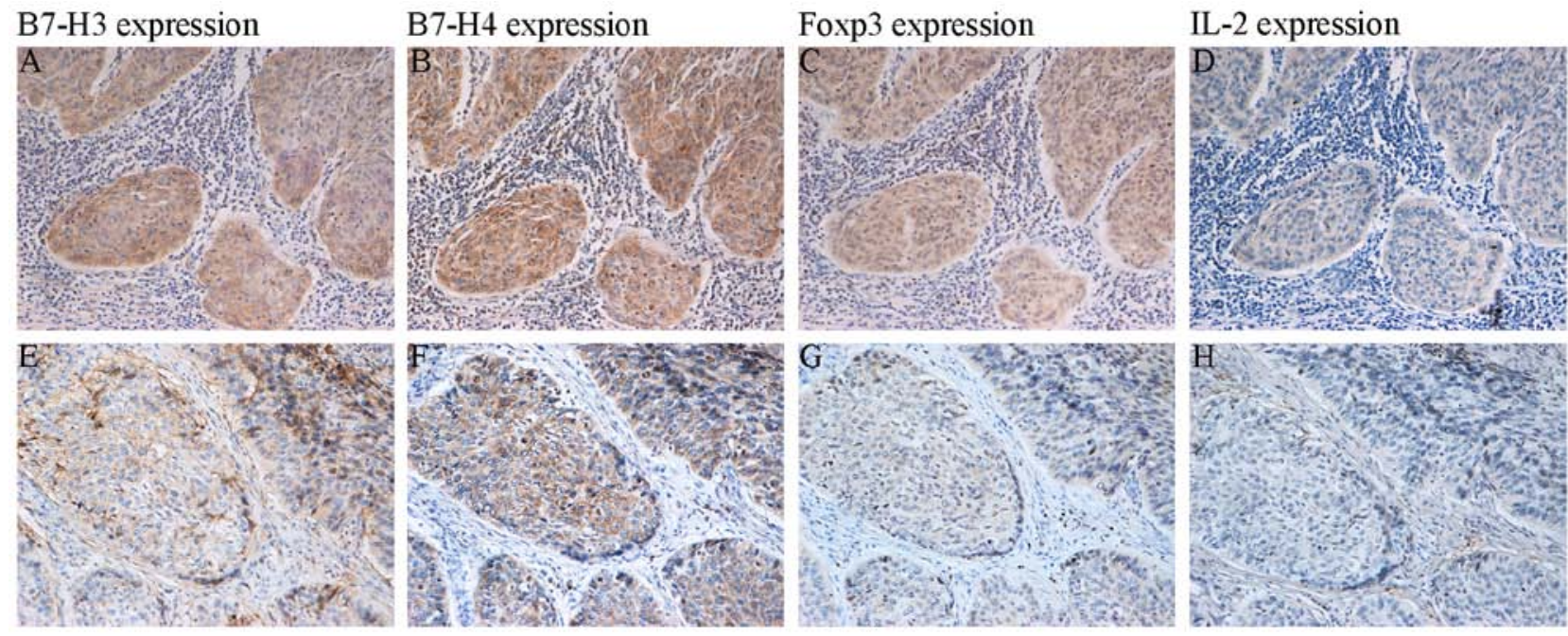

Figure 2. The relationship among the expression levels of B7-H3, B7-H4, Foxp3 and IL-2 antigens in the same cervical cancer tissues (magnification, x200). (A and E) B7-H3; (B and F) B7-H4; (C and G) Foxp3; (D and H) IL-2.

Table III. Correlation between B7-H3, B7-H4, Foxp3 and IL-2 expression in cervical cancer tissues.

\begin{tabular}{lcccc}
\hline $\begin{array}{l}\text { Spearman correlation } \\
\text { analysis (n=108) }\end{array}$ & B7-H3 & B7-H4 & Foxp3 & IL-2 \\
\hline B7-H3 & & & & \\
r & 1.000 & 0.489 & 0.366 & -0.296 \\
P-value & - & $<0.001^{\mathrm{a}}$ & $<0.001^{\mathrm{a}}$ & $0.002^{\mathrm{a}}$ \\
B7-H4 & & & & \\
$\quad$ r & 0.489 & 1.000 & 0.483 & -0.327 \\
P-value & $<0.001^{\mathrm{a}}$ & - & $<0.001^{\mathrm{a}}$ & $0.001^{\mathrm{a}}$ \\
Foxp3 & & & & \\
$\quad$ r & 0.366 & 0.483 & 1.000 & -0.105 \\
P-value & $<0.001^{\mathrm{a}}$ & $<0.001^{\mathrm{a}}$ & - & 0.280 \\
IL-2 & & & & \\
$\quad$ r & -0.296 & -0.327 & -0.105 & 1.000 \\
P-value & $0.002^{\mathrm{a}}$ & $0.001^{\mathrm{a}}$ & 0.280 & - \\
\hline
\end{tabular}

${ }^{\mathrm{a}} \mathrm{P}<0.05$. Spearman's correlation coefficient, $\mathrm{r}$.

is shown in Table III). The expression of B7-H3, B7-H4, Foxp3 and IL-2 in the same tissue is shown in Fig. 2.

The prognostic significance of B7-H3, B7-H4, Foxp3 and IL-2 in cervical cancer. Between January 2007 and May 2015, 36 (33.33\%) of the 108 patients died and $72(66.67 \%)$ were alive. The overall survival for patients with B7-H3/B7-H4/Foxp3-positive expression was significantly lower (Fig. 3). Univariate and multivariate analyses showed that there was a significant correlation between the expression of $\mathrm{B} 7-\mathrm{H} 3$ and $\mathrm{B} 7-\mathrm{H} 4$ and prognosis, but no correlation was noted between Foxp3 and IL-2 expression and prognosis in the cervical cancer patients (Table IV).

Age, FIGO stage, histologic type, histologic findings, lymph node metastasis, and tumor size were included in the multivariate overall survival analysis using Cox proportional
Table IV. Analysis of B7-H3, B7-H4, Foxp3 or IL-2 expression in relation to prognosis of patients with cervical cancer.

\begin{tabular}{lrlllll}
\hline & $\beta$-value & SE & P-value & OR value & \multicolumn{1}{c}{$95 \%$ CI } \\
\hline \multicolumn{2}{l}{ Univariate analysis } \\
B7-H3 & 2.174 & 0.729 & $0.003^{\mathrm{a}}$ & 8.793 & $2.108-36.674$ \\
B7-H4 & 2.643 & 1.024 & $0.010^{\mathrm{a}}$ & 14.049 & $1.890-104.443$ \\
Foxp3 & 1.445 & 1.016 & 0.155 & 4.241 & $0.579-31.038$ \\
IL-2 & -0.548 & 0.343 & 0.111 & 0.578 & $0.295-1.133$ \\
Multivariate analysis & & & & \\
B7-H3 & 1.882 & 0.749 & $0.012^{\mathrm{a}}$ & 6.567 & $1.512-28.528$ \\
B7-H4 & 2.101 & 1.053 & $0.046^{\mathrm{a}}$ & 8.172 & $1.038-64.340$
\end{tabular}

${ }^{\mathrm{a}} \mathrm{P}<0.05$. OR, odds ratio; $\mathrm{CI}$, confidence interval.

hazards analysis; however, the variables were not significantly associated.

\section{Discussion}

Cervical cancer is the second most common cancer in women. In recent years, there has been an increase in the number of studies involving the negative co-stimulatory factors, $\mathrm{B} 7-\mathrm{H} 3$ and $\mathrm{B} 7-\mathrm{H} 4$. The negative co-stimulatory effect of $\mathrm{B} 7-\mathrm{H} 3$ and B7-H4 on T cells has been confirmed (19-21). We speculated that both factors share one or several receptors due to their high similarity; however, the putative receptor has not been identified. Although the abnormal expression of both factors in a variety of tumor tissues has been previously reported, the expression in cervical cancer has been seldom studied. Wang et al (22) demonstrated that B7-H4 is not expressed in normal cervical epithelium, weakly expressed in CINII-III, but highly expressed in cervical cancer cells $(\mathrm{P}<0.05)$. Additionally, B7-H4 was found to be moderately expressed in mesenchymal cells in cervical cancer. In other studies, B7-H4 expression has been detected in the tumor microenvironment, 

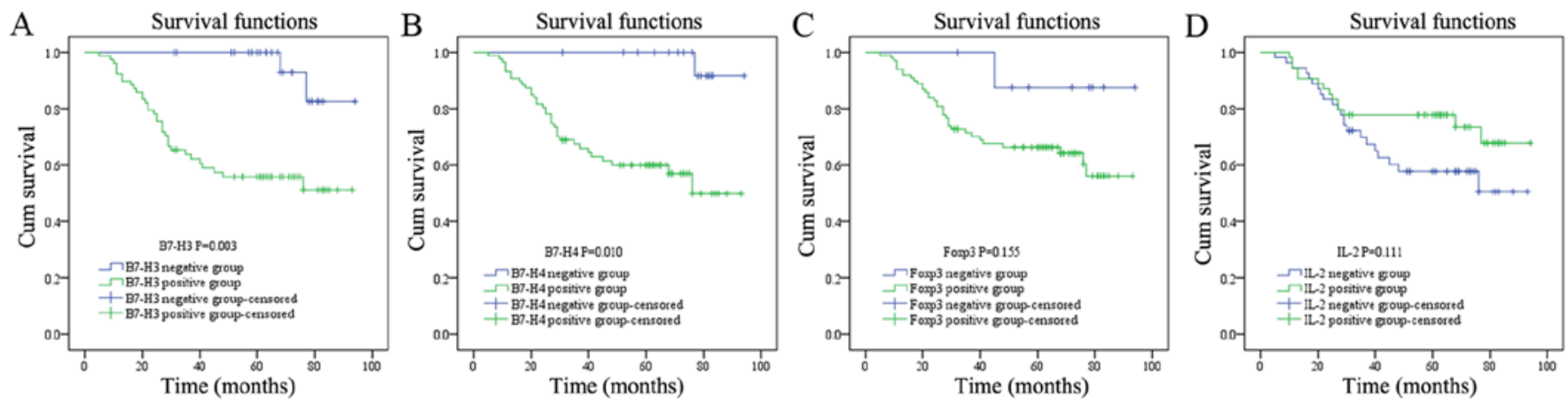

Figure 3. The association between overall survival and B7-H3, B7-H4, Foxp3 or IL-2 antigen expression in 108 patients with cervical cancer. (A-C) Patients with negative expression showed longer overall survival than those with positive expression of B7-H3, B7-H4 and Foxp3 ( $\mathrm{P}=0.003,0.010,0.155$, respectively). (D) Patients with positive IL-2 expression showed longer overall survival than those with negative expression ( $\mathrm{P}=0.111)$.

such as tumor-associated macrophages (2,23-25). In a study involving 102 cases of cervical cancer conducted by Liu et al (11), the rate of expression of B7-H4 in cervical cancer cells was reported to be high $(69.6 \%, 71 / 102)$, and B7-H4 was positively expressed in the cytoplasm and on the membrane of cervical cancer cells. Nevertheless, no correlation between B7-H4 expression and clinicopathologic factors was identified, including age, histologic type, and lymph node metastasis. In a study involving a large number of patients with prostate cancer, Zang et al (2) revealed the abnormally high expression of B7-H3 and B7-H4 in tumor tissues with positive expression rates of 93 and 99\%, respectively. The expression of B7-H3 and $\mathrm{B} 7-\mathrm{H} 4$ was also detected in the tumor microenvironment, such as macrophages and perivascular areas (small vessel endothelial cells). Consistent with these previous findings, our study demonstrated rates of expression of $72.22 \%(78 / 108)$ and $80.56 \%$ (87/108) for B7-H3 and B7-H4, respectively. Both proteins were also highly expressed in the tumor stroma. Moreover, it was shown that B7-H3 expression in cervical cancer was only correlated with tumor size among all of the clinicopathologic features evaluated and B7-H4 expression was correlated with tumor size and FIGO stage. Patients with a high level of B7-H3 and B7-H4 expression tended to have a worse prognosis; moreover, the difference in the prognosis between these patients and other patients was statistically significant. Furthermore, B7-H3 and B7-H4 expression were identified as independent risk factors for the clinical prognosis of cervical cancer.

Currently, the findings on the prognostic effect of B7-H3 are controversial. Most reports suggest that a high level of B7-H3 expression in tumor cells is associated with the progression and prognosis of the disease $(2,8,10,26-29)$, which was consistent with our results. Other studies demonstrated no correlation $(30,31)$. Low expression of $\mathrm{B} 7-\mathrm{H} 3$ in tumor stroma may facilitate escape of the antitumor immune response, whereas high B7-H3 expression prevents tumor progression. B7-H3 was also shown to suppress the antitumor immune response, which is in contrast to the previous finding. Another hypothesis suggests that interstitial B7-H3 inhibits the progression of tumors through an unknown non-immune mechanism. Overall, the effect of B7-H3 as a prognostic marker in cancer is uncertain. The inconsistent findings in the literature may be associated with the different methodology used in these studies or different functions of B7-H3 in different forms of cancer.

Regulatory $\mathrm{T}$ cells (Treg cells) are a class of immunosuppressive cells involved in tumor immune escape. Foxp3 (transcription factor forkhead box P3) is the specific surface marker of Treg cells (32). The increased number of Foxp3 ${ }^{+}$ Treg cells in tumor tissues is correlated with poor prognosis $(13,14)$. Geng et al (33) reported that the expression of B7-H1 and B7-H4 in gastric cancer is positively correlated with interstitial Foxp3 expression. Wang et al (22) demonstrated that the proportion of $\mathrm{CD}^{2} 5^{+} \mathrm{Foxp}^{+} \mathrm{T}$ cells in $\mathrm{CD} 4^{+}$ $\mathrm{T}$ cells is significantly increased after a 48 -h co-culture with B7-H4, suggesting that B7-H4 can promote the proliferation of Treg cells. Luo et al (34) found in a further study that Foxp3 had a high expression in cervical cancer cells and tumor interstitium, moreover was able to facilitate the proliferation and invasiveness of $\mathrm{SiHa}$ cells, alter the cell cycle and inhibit their apoptosis. In our study, it was shown that the expression of B7-H3 and B7-H4 in cervical cancer cells was positively correlated with Foxp3 expression. On the one hand, B7-H3 and B7-H4 may mediate tumor immune escape by increasing the number of Treg cells, thereby promoting the progression of tumors. On the other hand, high expression levels of B7-H3 and B7-H4 upregulate Foxp3 expression in cervical cancer cells, which regulates the occurrence and development of tumors by affecting the proliferation and apoptosis of cancer cells. From the perspective of immunotherapy, inhibition of B7-H3 and B7-H4 expression may reduce or block the proliferation of Treg cells, leading to antitumor effects. Nevertheless, the mechanism underlying the stimulatory effect of B7-H3 and B7-H4 on Foxp3 expression has yet to be elucidated. Our results suggest that high expression of Foxp3 is associated with prognosis in cervical cancer patients. Rather, as discussed above, not only an increase in Treg cell numbers but also a high level of expression in tumor cells may be clearly correlated with prognosis. IL-2 is a key cytokine involved in the immune response. IL-2 regulation promotes the differentiation of T cells and enhances the killing effect. Decreased IL-2 expression has a lower regulatory effect on the proliferation and differentiation of $\mathrm{T}$ lymphocytes, leading to a reduced antitumor effect of $\mathrm{T}$ cells and dysfunction of cellular immunity. Our study showed that the expression of B7-H3, B7-H4 and Foxp3 is negatively correlated with IL-2 expression, suggesting that the immune 
inhibition of B7-H3, B7-H4 and Foxp3 may be achieved by promoting the proliferation of Treg cells, upregulating Foxp3 expression in cervical cancer cells, or directly suppressing the secretion of IL-2. It was also shown that the immune response in cervical cancer patients with B7-H3, B7-H4 and Foxp3 expression was less than patients with negative expression of B7-H3, B7-H4 and Foxp3.

In conclusion, several studies, including our study, have reported abnormally high expression of B7-H3 and B7-H4 in various human malignant cells, which may be a promising target for cancer immunotherapy (7,29,35-40). An association of B7-H3 and B7-H4 expression with reduced survival in cervical cancer patients was found. Although immunotherapy based on inhibition of T cell signaling by blocking CTLA-4 has been applied in the treatment of hormone-refractory prostate cancer (41), multiple molecular therapeutic targets are involved for effective immunomodulation. Based on our results, we suggest that blocking B7-H4 may be more efficient compared with blocking B7-H3 in the treatment of cervical cancer.

\section{Acknowledgements}

This study was supported by the National Nature Science Foundation of China (grant no. 81372776), the Science and Technology Program of Liaoning Province (grant no. 2011225009), the Higher Specialized Research Fund for the Doctoral Program (grant no. 20122104110014), and the Free Researcher Project of Shengjing Hospital (grant no. 201302).

\section{References}

1. Torre LA, Bray F, Siegel RL, Ferlay J, Lortet-Tieulent J and Jemal A: Global cancer statistics, 2012. CA Cancer J Clin 65: 87-108, 2015.

2. Zang X, Thompson RH, Al-Ahmadie HA, Serio AM, Reuter VE, Eastham JA, Scardino PT, Sharma P and Allison JP: B7-H3 and B7x are highly expressed in human prostate cancer and associated with disease spread and poor outcome. Proc Natl Acad Sci USA 104: 19458-19463, 2007.

3. Tsiaousidou A, Lambropoulou M, Chatzitheoklitos E, Tripsianis G, Tsompanidou C, Simopoulos C and Tsaroucha AK: B7H4, HSP27 and DJ-1 molecular markers as prognostic factors in pancreatic cancer. Pancreatology 13: 564-569, 2013.

4. Zhao X, Li DC, Zhu XG, Gan WJ, Li Z, Xiong F, Zhang ZX, Zhang GB, Zhang XG and Zhao H: B7-H3 overexpression in pancreatic cancer promotes tumor progression. Int J Mol Med 31: 283-291, 2013

5. Sun Y, Wang Y, Zhao J, Gu M, Giscombe R, Lefvert AK and Wang X: B7-H3 and B7-H4 expression in non-small-cell lung cancer. Lung Cancer 53: 143-151, 2006.

6. Schneider T, Hoffmann H, Dienemann H, Schnabel PA, Enk AH, Ring S and Mahnke K: Non-small cell lung cancer induces an immunosuppressive phenotype of dendritic cells in tumor microenvironment by upregulating B7-H3. J Thorac Oncol 6: 1162-1168, 2011

7. Krambeck AE, Thompson RH, Dong H, Lohse CM, Park ES, Kuntz SM, Leibovich BC, Blute ML, Cheville JC and Kwon ED: B7-H4 expression in renal cell carcinoma and tumor vasculature: Associations with cancer progression and survival. Proc Natl Acad Sci USA 103: 10391-10396, 2006.

8. Crispen PL, Sheinin Y, Roth TJ, Lohse CM, Kuntz SM, Frigola X, Thompson RH, Boorjian SA, Dong H, Leibovich BC, et al: Tumor cell and tumor vasculature expression of $\mathrm{B} 7-\mathrm{H} 3$ predict survival in clear cell renal cell carcinoma. Clin Cancer Res 14: 5150-5157, 2008.

9. Simon I, Zhuo S, Corral L, Diamandis EP, Sarno MJ, Wolfert RL and Kim NW: B7-h4 is a novel membrane-bound protein and a candidate serum and tissue biomarker for ovarian cancer. Cancer Res 66: 1570-1575, 2006.
10. Zang X, Sullivan PS, Soslow RA, Waitz R, Reuter VE, Wilton A, Thaler HT, Arul M, Slovin SF, Wei J, et al: Tumor associated endothelial expression of B7-H3 predicts survival in ovarian carcinomas. Mod Pathol 23: 1104-1112, 2010.

11. Liu W, Shibata K, Koya Y, Kajiyama H, Senga T, Yamashita M and Kikkawa F: B7-H4 overexpression correlates with a poor prognosis for cervical cancer patients. Mol Clin Oncol 2: 219-225, 2014.

12. Mailloux AW and Young MR: Regulatory T-cell trafficking: From thymic development to tumor-induced immune suppression. Crit Rev Immunol 30: 435-447, 2010.

13. Lu X, Liu J, Li H, Li W, Wang X, Ma J, Tong Q, Wu K and Wang G: Conversion of intratumoral regulatory $T$ cells by human gastric cancer cells is dependent on transforming growth factor- $\beta 1$. J Surg Oncol 104: 571-577, 2011.

14. Woo EY, Chu CS, Goletz TJ, Schlienger K, Yeh H, Coukos G, Rubin SC, Kaiser LR and June CH: Regulatory CD4(+)CD25(+) $\mathrm{T}$ cells in tumors from patients with early-stage non-small cell lung cancer and late-stage ovarian cancer. Cancer Res 61: 4766-4772, 2001

15. Wang HY and Wang RF: Regulatory T cells and cancer. Curr Opin Immunol 19: 217-223, 2007.

16. Hinz S, Pagerols-Raluy L, Oberg HH, Ammerpohl O, Grüssel S, Sipos B, Grützmann R, Pilarsky C, Ungefroren H, Saeger HD, et al: Foxp3 expression in pancreatic carcinoma cells as a novel mechanism of immune evasion in cancer. Cancer Res 67: 8344-8350, 2007.

17. Wang L, Liu R, Li W, Chen C, Katoh H, Chen GY, McNally B, Lin L, Zhou P, Zuo T, et al: Somatic single hits inactivate the X-linked tumor suppressor FOXP3 in the prostate. Cancer Cell 16: 336-346, 2009.

18. Wang LH, Su L and Wang JT: Correlation between elevated FOXP3 expression and increased lymph node metastasis of gastric cancer. Chin Med J (Engl) 123: 3545-3549, 2010.

19. Zang X, Loke P, Kim J, Murphy K, Waitz R and Allison JP: B7x: A widely expressed B7 family member that inhibits T cell activation. Proc Natl Acad Sci USA 100: 10388-10392, 2003.

20. Sica GL, Choi IH, Zhu G, Tamada K, Wang SD, Tamura H, Chapoval AI, Flies DB, Bajorath J and Chen L: B7-H4, a molecule of the B7 family, negatively regulates $\mathrm{T}$ cell immunity. Immunity 18: 849-861, 2003.

21. Prasad DV, Richards S, Mai XM and Dong C: B7S1, a novel B7 family member that negatively regulates $\mathrm{T}$ cell activation. Immunity 18: 863-873, 2003.

22. Wang X, Wang T, Xu M, Xiao L, Luo Y, Huang W, Zhang Y and Geng W: B7-H4 overexpression impairs the immune response of T cells in human cervical carcinomas. Hum Immunol 75: 1203-1209, 2014

23. Kryczek I, Wei S, Zhu G, Myers L, Mottram P, Cheng P, Chen L, Coukos $\mathrm{G}$ and Zou W: Relationship between B7-H4, regulatory T cells, and patient outcome in human ovarian carcinoma. Cancer Res 67: 8900-8905, 2007.

24. Kryczek I, Zou L, Rodriguez P, Zhu G, Wei S, Mottram P, Brumlik M, Cheng P, Curiel T, Myers L, et al: B7-H4 expression identifies a novel suppressive macrophage population in human ovarian carcinoma. J Exp Med 203: 871-881, 2006.

25. Galazka K, Opławski M, Windorbska W, Skret-Magierlo J, Koper K, Basta P, Mach P, Dutch-Wicherek M, Mazur A and Wicherek L: The immunohistochemical analysis of antigens such as RCAS1 and B7H4 in the cervical cancer nest and within the fibroblasts and macrophages infiltrating the cancer microenvironment. Am J Reprod Immunol 68: 85-93, 2012.

26. Yamato I, Sho M, Nomi T, Akahori T, Shimada K, Hotta K, Kanehiro H, Konishi N, Yagita H and Nakajima Y: Clinical importance of B7-H3 expression in human pancreatic cancer. Br J Cancer 101: 1709-1716, 2009.

27. Arigami T, Narita N, Mizuno R, Nguyen L, Ye X, Chung A, Giuliano AE and Hoon DS: B7-h3 ligand expression by primary breast cancer and associated with regional nodal metastasis. Ann Surg 252: 1044-1051, 2010.

28. Sun TW, Gao Q, Qiu SJ, Zhou J, Wang XY, Yi Y, Shi JY, Xu YF, Shi YH, Song K, et al: B7-H3 is expressed in human hepatocellular carcinoma and is associated with tumor aggressiveness and postoperative recurrence. Cancer Immunol Immunother 61: 2171-2182, 2012.

29. Roth TJ, Sheinin Y, Lohse CM, Kuntz SM, Frigola X, Inman BA, Krambeck AE, McKenney ME, Karnes RJ, Blute ML, et al: B7-H3 ligand expression by prostate cancer: A novel marker of prognosis and potential target for therapy. Cancer Res 67: 7893-7900, 2007. 
30. Quandt D, Fiedler E, Boettcher D, Marsch WC and Seliger B B7-h4 expression in human melanoma: Its association with patients' survival and antitumor immune response. Clin Cancer Res 17: 3100-3111, 2011.

31. Boland JM, Kwon ED, Harrington SM, Wampfler JA, Tang H, Yang P and Aubry MC: Tumor B7-H1 and B7-H3 expression in squamous cell carcinoma of the lung. Clin Lung Cancer 14: 157-163, 2013

32. Strauss L, Bergmann C, Szczepanski M, Gooding W, Johnson JT and Whiteside TL: A unique subset of $C D 4^{+} \mathrm{CD} 25^{\text {high }} \mathrm{Foxp} 3^{+}$ $\mathrm{T}$ cells secreting interleukin-10 and transforming growth factor-beta1 mediates suppression in the tumor microenvironment. Clin Cancer Res 13: 4345-4354, 2007.

33. Geng Y, Wang H, Lu C, Li Q, Xu B, Jiang J and Wu C: Expression of costimulatory molecules B7-H1, B7-H4 and Foxp3 ${ }^{+}$Tregs in gastric cancer and its clinical significance. Int J Clin Oncol 20: 273-281, 2015.

34. Luo Q, Zhang S, Wei H, Pang X and Zhang H: Roles of Foxp3 in the occurrence and development of cervical cancer. Int J Clin Exp Pathol 8: 8717-8730, 2015.

35. Chen L: Co-inhibitory molecules of the B7-CD28 family in the control of T-cell immunity. Nat Rev Immunol 4: 336-347, 2004.

36. Zang X and Allison JP: The B7 family and cancer therapy: Costimulation and coinhibition. Clin Cancer Res 13: 5271-5279, 2007.
37. Choi IH, Zhu G, Sica GL, Strome SE, Cheville JC, Lau JS, Zhu Y, Flies DB, Tamada $\mathrm{K}$ and Chen L: Genomic organization and expression analysis of $\mathrm{B} 7-\mathrm{H} 4$, an immune inhibitory molecule of the B7 family. J Immunol 171: 4650-4654, 2003.

38. Tringler B, Zhuo S, Pilkington G, Torkko KC, Singh M, Lucia MS Heinz DE, Papkoff J and Shroyer KR: B7-h4 is highly expressed in ductal and lobular breast cancer. Clin Cancer Res 11: 18421848,2005

39. Tringler B, Liu W, Corral L, Torkko KC, Enomoto T, Davidson S, Lucia MS, Heinz DE, Papkoff J and Shroyer KR: B7-H4 overexpression in ovarian tumors. Gynecol Oncol 100: 44-52, 2006.

40. Miyatake T, Tringler B, Liu W, Liu SH, Papkoff J, Enomoto T, Torkko KC, Dehn DL, Swisher A and Shroyer KR: B7-H4 (DD-O110) is overexpressed in high risk uterine endometrioid adenocarcinomas and inversely correlated with tumor T-cell infiltration. Gynecol Oncol 106: 119-127, 2007.

41. Small EJ, Tchekmedyian NS, Rini BI, Fong L, Lowy I and Allison JP: A pilot trial of CTLA-4 blockade with human anti-CTLA-4 in patients with hormone-refractory prostate cancer. Clin Cancer Res 13: 1810-1815, 2007. 